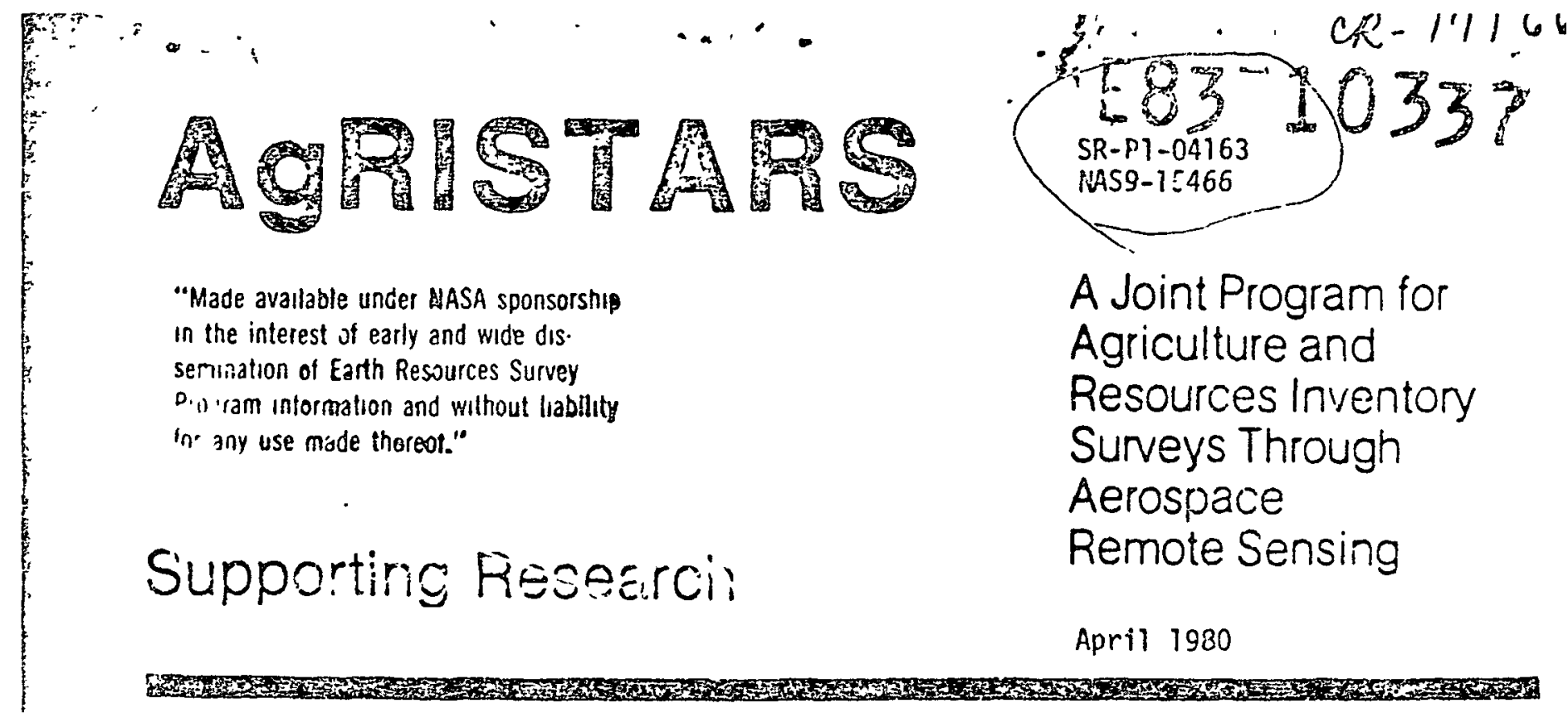

ANAL:TICAL DESIGN OF MULTISPECTRAL SENSORS

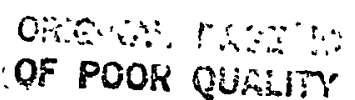

D. J. Wiersma, D. A. Landgrebe
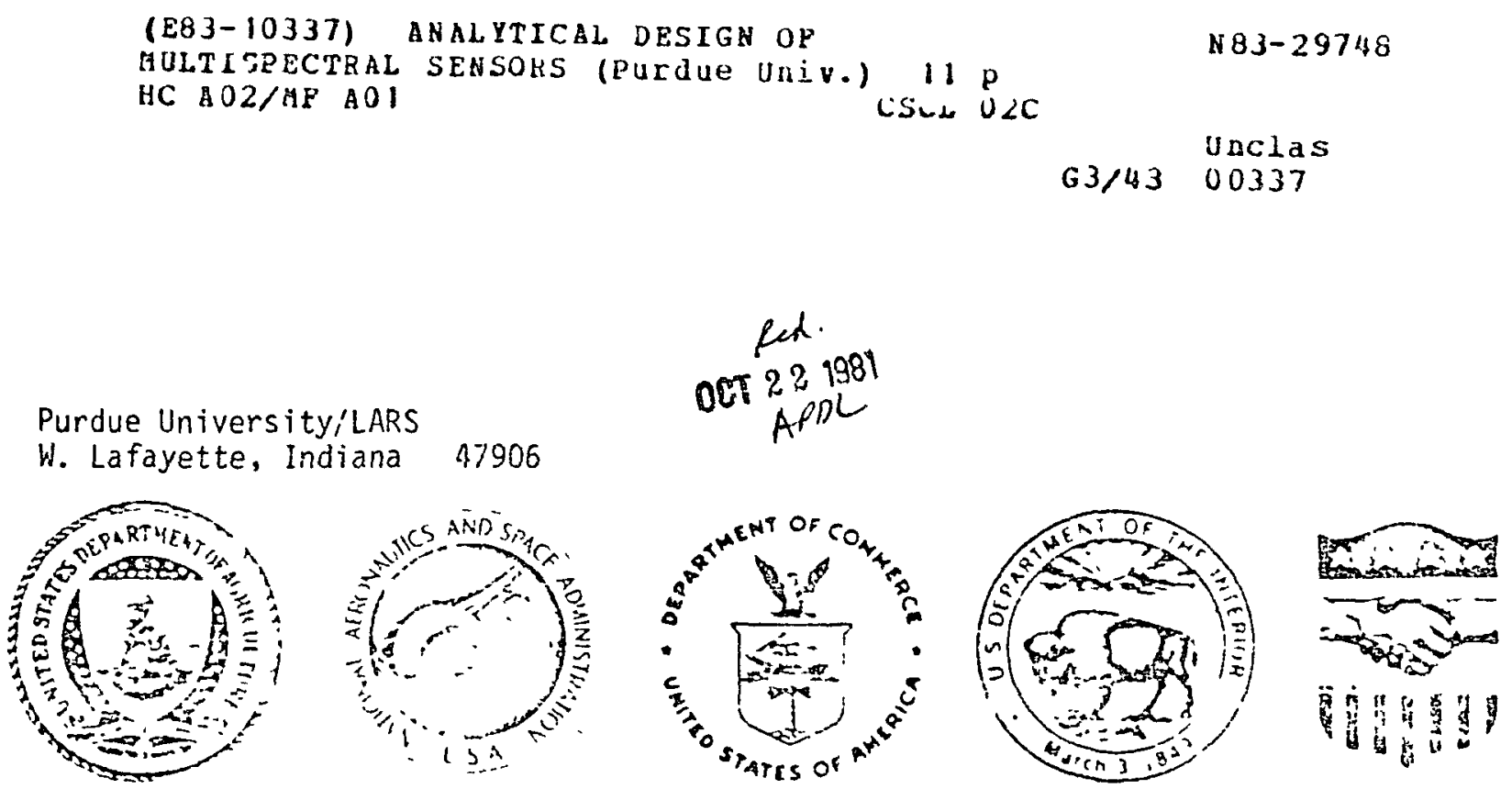

Lyndon B. Jorinson Space Center

Houston, Texas 77058 


\title{
Analytical Design of Multispectral Sensors
}

\author{
DANIEL J WIERSMA, MEMBER, IEEE, AND DAVID A LANDGREBE, FELLOW, IELE
}

\begin{abstract}
Abstroct-An analytical r occdure for the design of the spectral channets for muluspectral remrie sensor systems is defined. An optimal design based on the criterion of minimum mean-square representation enror using the Karhunen-Loeve expansion was devcloped to represent the spectral response functions from a stratum based upon a stochastic process scene model. From the overall pattern recognition svstem perspective the effect of the representation accuracy on a typical performance critenon, the probabihty of correct classification, is investigated. The optımum sensor design provides a standard aganst which pracical (suboptimum) operational sensors can be compared. An example design is provided and its performance is illustrated.

Although the analytical technique was developed primarty for the purpose of senvor design it was found that the procedure has potential for makung important contributions to scene understanding. It was concluded that spectral channels which have narrow bandwidths relative to current sensor systems may be necessary to provide adequate spectral representation and improved classification performance.
\end{abstract}

\section{INTRODUCTION}

A PATTERN recognition system as used in a remotc sensing system for earth resources consists of three fundamental components-the scene, the sensor, and the processor (Fig 1) The scene is that portion of the earth's surface observed by the sensor The desired information is contained in the spectral, spatial, and tempord vartations of the elcctromagnetic energy emanating from the scene The sensor collects the energy and measures its features The processor is typically a digtally implemented classification algonthm which makes in appropnate decision based on the feature measurements provided by the output from the sensor Var1ous typas of arcillary data are also now typically used in the decision-making process

At present the design of the processor algorithms is quite advanced and provides variety and fexibility for optumal performance given a feature set [4], [5] However, the design of the best set of features is a complex matter which is not well understood There dre many sensor parameters involved [1], ch 7] In the current work we limit considerations to the design of the spectral aspects of features to make the problem more tracrable, leaving other aspects to later occasions

Manuscript received January 4, 1979, revised December 7, 1979 This work w'as supported by NASA/Johnson Space Center under Contracts NAS9-14970 and NAS9-15466

D J Wiersma was with the Department of Electrical kngineering and the Luhoratury for Applications of Remote Sensing (LARS), Purdue Universty, Lafugette. IN lle is now with the Minneapo.s lloncywell Compans, Minneapolis, MN

D A Landgrche is with the Depurtment of Electrical Enguncring and the Lahoratory for Applications of Remote Sensing. Purdue Un:"ersity, Weut Lafayctle, IN 47907

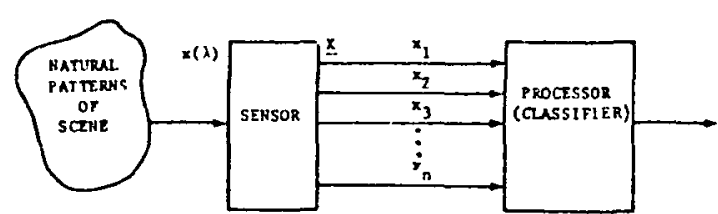

rig I Tallcrn recognition system

\section{Silctral Rerrish ntation and Optimum SENSOR DFSIGN}

In order to achueve an optumal design of a set of spectral features one must have sutatie andytical representutions for 1) the spectral response of the scene, 2) the sensor system, 3) the processor system, and 4) one must have a surtable, analytically expressible optumality criterion Further, we note the following factors which influence the creation of a spectral feature design procedure

1) The scene is very complex in the fashon in which it reflects and emus optical radiation Mathenatical models whuch predict the scene radiant exitance ai least to the level of ascuracy and precision needed for our problein, co not yet exist As a result an compirical scene model must be used

2) Because satellite-borne sensor sy'stems are very expensive they cannot usually be designed specifically for a ceitain use or user Rather they must be optumized with regard to a large number of scencs and uses ( $F_{1 g} 2$ ) The feature space which the sensor defines inust be adequately detaled, for cxample, such that in cally season when dgricultui 1 crop canopies have acheved only 10-15-percent cover, both the crop species mapping user and the solls mapper can be served This fact is important in the chouce of optimaity criterion, as will be seen shorily

3) It is highly desirable that the spectral features be designed in such a way that they are maxumally efficient in the sense that a feature set of any given size contain the maximum amount of useful information possible so that any geven analysis can proceed with the smallest number of features possible There are at least three reasons for this feature efficiency in this sense tends to decrease the amount of processor computation tequred, it tends to decrease the processor complexity required, and it tends to reduce the amount of training sample data needed

4) There are a number of constrants on the design of a sensor, generally of a practucal character, which cannot reasonably be expressed analytically Examples are tiose resulting from optical design considerations, sensor material sensitivity curves, cost fictors, spacecraft sizc and weight 


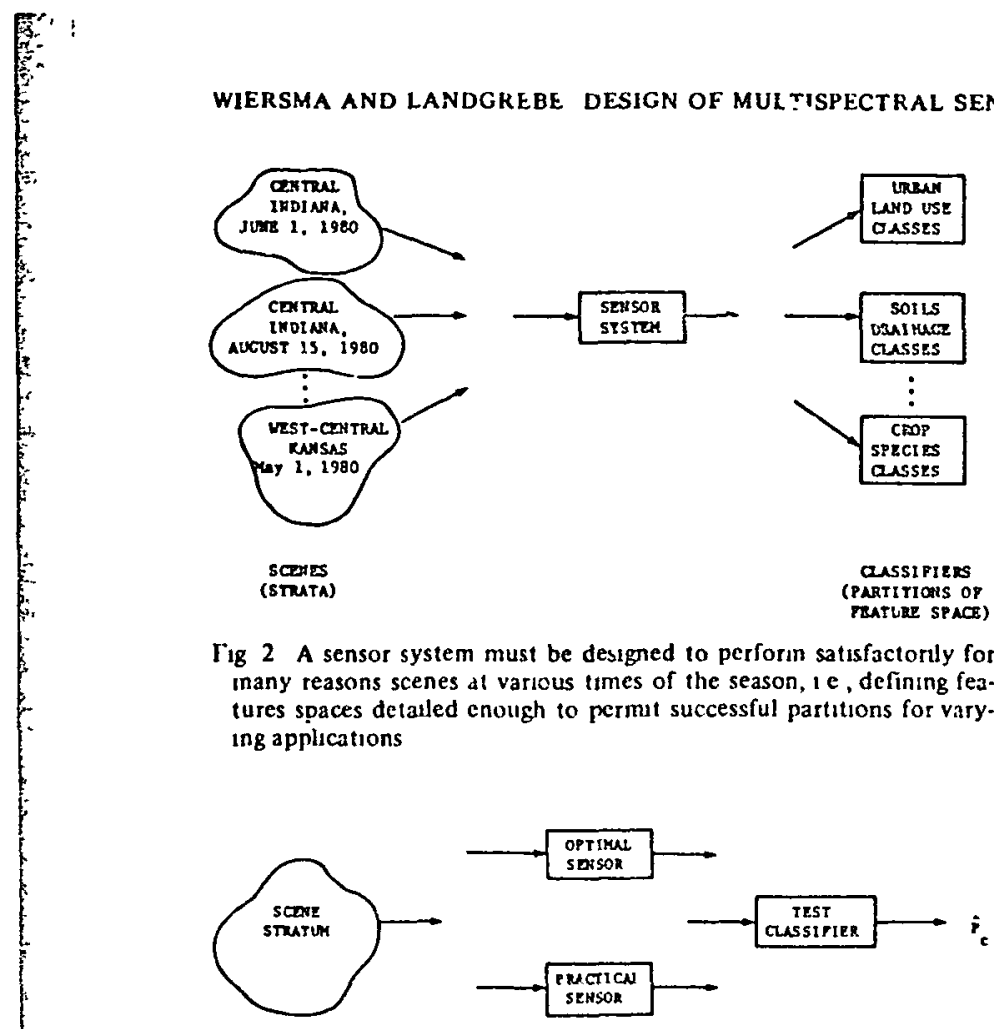

Fig 3 Sensor sysizm design procedure

considerations, etc, and especially from the interrelationships of these types of factors To mitigate thus circumstance we will use the scleme depicted in Fig 3. That is, we will determine optimal sensor chdracienstics using enturely analyical means without regard for their physical realizability These characteristics will then serve as a guide by which to determine nearly equvalent but phy'sically realizable characternstics which perform near'y as well

In order to achueve the desired spectral feature design scheme we must deal specifically with each of these lettered and numbered items above

\section{A The Scene Model}

Let us begin by considering the information beanng aspects of the spectral response function $x(\lambda)[8]$ This response function (e $\mathrm{g}$, from a single pixel) is proportional to the electromagnetic energy recersed by the sensor as a function of wavelength $\lambda$ (Fig 4) Many factors determine the spectral response function for a given observation The rradiance of the sun, the conditions of the atmosphere, and the reflectance of the surfacc features all have important effects on the response Since a deterministic relationship between the response function and the many factors affecting 1 would be very complex, the set of functions which are observed in practice are best modeled as a stochastic process

The ensemble 0 ? the stochastic process [13] wll be defined in terms of the stratification necessary to apply pattern recog nition methods to the earth observational problem A stratum $S$ is defined as the largest contuguous area wluch can be classi. fied to an acceptable level of performance with a single train

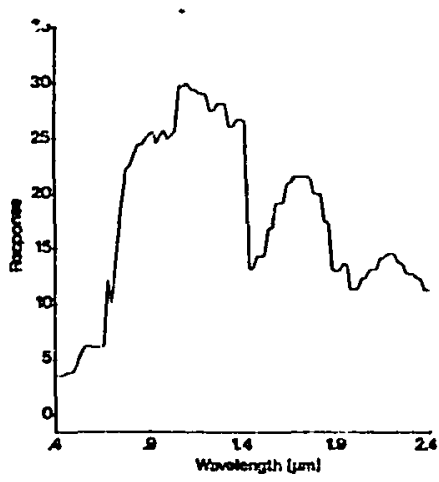

Fig 4 Spectral response function for Mature Wheat collected on August 4, 1977, over Wultams County, ND

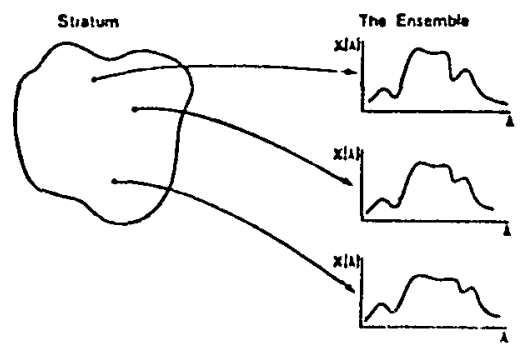

Fig 5 Realization of a strdium as the ensemble of spectral sample functions

Ing of the classifier It is noted that the sensor must be designed to operate satisfactorily over a large number of such strata, which vary greatly with time, location and application The collection of all possible strata which a sensor may observe is dennted by $S_{0}$ Since the set $S_{0}$ is quite large, it is necessary to select a smaller subset which is representative in a statistical sense in order to perform the design

The random experument for the stochastic process consists of the observation of a point in a siratum $S$ Each poini in the stratum is mapped into a spectral response function (Fig 5 ) The collection of all response functions from a stratum defines an ensemble The ensemble plus the corresponding piobability measure defines the stochastic process [13] It is appropriate to assume a Gdussian probability measure for thus process [3].

\section{$B$ The Sersor System Model}

Next we choose a mathematical model for the sensor to represent the spectral response funcuon for each observation Let the sensor be represented by a set of $N$ filter functions or basis functions $\left\{\phi_{1}(\lambda)\right\}$ such that the output of each fiuter is given by (Fig. 6)

$$
x_{1}=\int_{\Lambda} \lambda(\lambda) \phi_{1}(\lambda) d \lambda
$$

The output of the senscr model is a sequence, $\left\{x_{1}, x_{2}\right.$, , $\left.x_{N}\right\}=X$, which represents the spectral response by the 
A simple illustration of the concept is given in Fig 7 How. ever, by relaxing the usual restrictions on the shape of the $\left\{\phi_{n}(\lambda)\right\}$, considerable advantage can be obtaned There is no theorctical or pracucal reasun, for example, for the $\left\{\phi_{n}(\lambda)\right\}$ to be nonoverlappung What is necded is to ducermine the ordered set of busis functions which are optımal with regard to a meaningful system performance cutterion

\section{The Optumaluty Crtenon Including the Processor Model}

A key consideration is the choice of the optumality cnterion It is desirable to optumize the sensor design with respect to an overall system (including the scene and processor) per formance criterion The probability of correct classification is the cri. terion to be used here This choice is made because it is an ob. jective indicator of desired performince in a practical sense for d large proportion of applications, and it is perhaps the best studied and undersiond in a thruretical sense In selecting this performance measure there must also be associated with it a processor (classifier) model, in this ase we chose the maxsmun likeluhood rule, for the same reasons

However, because of the design factor pointed out in item (2) dnd Fig 2, we find it desirable to define an intermediate opumaluty criterion Because the sensor m.ist function over a varied collection of strata using anv if a large collection of classificis, a critcrion was chosen which is a measure of the

fidelity with which the output of the sensor represents the input $W e$ will choose the set $\left\{\phi_{1}(\lambda)\right\}$ such that for a given $x(\lambda)$ the approximation $\hat{x}(\lambda)$ is as close as possible to the truc spectral response function One may think of this approach as one intended to minimize the information loss through the sensor even though it cannot be known to the sensor designet what the information is Ir passing from $x(\lambda)$ to $\left\{x_{1}\right\}$ there is no information loss if $x(\lambda)$ is recoverable from $\left\{x_{1}\right\}$

A common criterion for representation accuracy is the ex. pected mean-square representation error given by

$$
E\left\{\epsilon_{r}\right]=E\left\{\int_{\Lambda}[x(\lambda)-\hat{x}(\lambda)]^{2} d \lambda\right\}
$$

However, it is desirable at this point to generalize :his criterion by introducing a weight function $w(\lambda$; on the spectral interval As will be seen, the weight associated with each $\lambda$ can be used to introduce into the analysis a pnon knowledge curcerning the spectrum Thus (1) and (3) become [16].

$$
\begin{aligned}
x_{1} & =\int_{\Lambda} x(\lambda) \phi_{1}(\lambda) w(\lambda) d \lambda \\
E\left\{\epsilon_{r}\right\} & =E\left\{\int_{\Lambda}[x(\lambda)-\hat{x}(\lambda)]^{2} w(\lambda) d \lambda\right\}
\end{aligned}
$$

We want to choose the set of basis functions $\left\{\phi_{1}(\lambda)\right\}$ which 1s optumal with respect to the speciral iepiesentat. on criterion of expected medn-square erro: $t\left\{c_{r}\right\}$ Micie specifically, it is desired that the representation be complete in the sense that the expected mean-squate error for any function in the ensemble be made arbitraily small sumply by including enough terms, that convergence of the approximation to the onginal response be rapid in the first few terms, and, without loss of generahty, we may also ask that the basis functions be orthogonal to each other

A technique for determing the set of optumal basis func$t_{1}$ uns for an ensemble which sausfies the desired propeitues is bused on the weighted Karhunen-Loeve expansion [2], [16], [17] The solution to the homogeneous linear integral equation is

$$
\gamma_{1} \phi_{2}(\lambda)=\int_{\Lambda} K(\lambda, \xi) \phi_{1}(\xi) w(\xi) d \xi
$$

with the covariance function of the stochastic process, $K(\lambda, \xi)$, as kernel is a set of eigenfunctions $\left\{\phi_{1}(\lambda)\right\}$ with corresponding eigenvalues $\gamma_{1}$ if the eigenvalues are arranged in descending order, the corrasponding sequence of eigenfuinctions can be used to form a linear combination of the eigenfunctions which converges to the onginal spectral response function with arbitrarly small expected mean-square error Furthermore, bccause of the orderng of the etgenvalues, convergence in the first few terms is very rapid This rap'd convergenre altows truncation of the serles cxpansion after a finite number of terms $N$ with medi-square error minmuzed over all possible choices of $N$ basis functions The mean square error is given by

$$
E\left\{\epsilon_{r}\right\}=\sum_{i=N+1}^{\infty} \gamma_{i}
$$




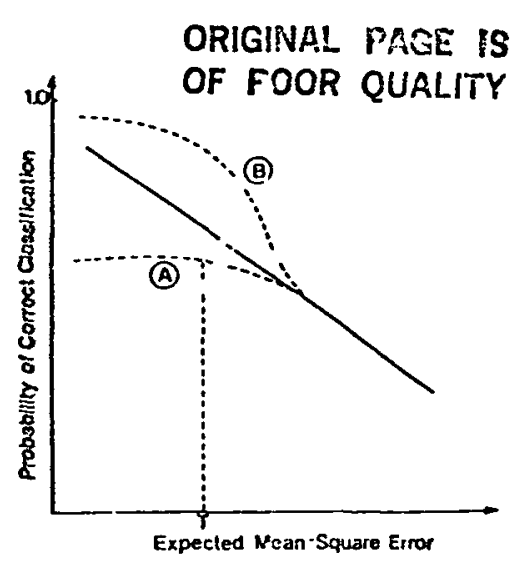

Itg 8 Probability of a correct classification as a funzuson of expected mean-square representation error

the performance provided that the stochastic process is completely known If after $N$ terms the improvement in performance is small compared to the reduction in representation etror, then the representation is sufficient This is illustrated by case $A$ of Fig $8 \mathrm{~m}$ which the :hreshold $T$ indicates the minimuin required $E\left[\epsilon_{r}\right]$ However, if the performance is showng stgmficant improvement for a small diviase in the mean-square crror, case $B$ of $F_{1 g} 8$, mo,e terms are necessary to complete the representation

Since the parimeters of the stochistic process must be estimated from i sample of the ensemble, the effect of the size of the sample relative to the dimensionality of the system is inportant Hughes $[10]$ has shown that if the sample size is too stiall, the classification performance may actually be degraded by adding terms to the expansion Thus it is necessary to montain a large set of sample functions from whuch to est1mate the statistics

The chorce of information clusses also influences the performance of the pattern recogrution system For purposes of classifying the data, - to distinct classes it is required that the class list have the following properties smultaneously [11]

1) Each class must be of interest to the user, ic, of informational value

2) The classes must be separable in terms of the features avalable

3) The list must be exhaustive, $1 \mathrm{e}$, there nust be a class to which it is logical to assign each pixel in the scene

The classes may be arranged in a luerarchal tree structure in which case classes decper in the tree require different representation accuracies to acheve a given level of classification performance

The area of the ground resolution element is determined by such sysiem chardcteristics as the instantaneous field-o ${ }^{r}$-vicw (IFOV), the altitude of the sensor, the scan rate, and the velocity of the sensor These are examples of spatial representa. tion parameters The size of the objects which can be identified and the eneray avallable are influenced by the choce of ground resolution element size. If a typical object which one wishes 10 identify is smaller than the ground resolution elemont sirc, then it is very difficult to ciassify that object Mobassen [12] has muestigated the effect of the area of the formance must be determmed It can be shown that increasing the number of terms in the representation will never decrease briefly discuss some of 115 characteristics

The addition of terms to the series expansion causes a monotonic decrease in the spectral representation error, but density function for class, The integral in (7) is over the The analytical procedure based on the weighted KarhunenLeve expansion lids prescribed a sensur design which to know how the ability to represent a process influences the cldssification performance To study this relationship the graph of the probability of correct classification versus $c x$. pected inean-squars error is introduced (Fig 8) We will

Since the unmodified $(w(\lambda)=1)$ Karhunen-Locve expansion is
a well-studied techinique and satisfies the desired propertics for a pron probabilities $P_{1}$, the probability of correct classifica-$$
P_{r}=\int \operatorname{mix}_{1}\left\{P_{1} p\left(X \mid C_{1}\right)\right\} d X
$$ 
IEEE TRANSACTIONS ON GCOSCIENCE AND REMOTE SENSING, VOL GE-18, NO 2, APRIL :983

resolution element on classification performance Increasing the ared often :mproves the signal-to-noise ratio which in turn can improve the classification performance

For a given remote sensing problem the stgnal is the part of the received response which is information bearing, and the noise is that part which is noninformation beanng The innuence of the s'gnal-to-notse ratio where the noise is white, Gaussian and additive was demonstra.ed by Ready et al [14] Results show that overall classification performance decreased with an increase in the noise level A class which was difficult to identify under low nuise level conditions suffered the most degradation when noise was added

\section{Experimfntal Systrm}

An experimental software system has been set up to implement the andytical procedure that has been developed The sottwate system has been implemented on an IBM 370 computer at the Laboratory for Applications of Remote Sensing (LARS) at Purdue University, Lafayctte, IN

A collection of field data consisting of spectral response functions on three dates from Willams County. ND, and three dates from Finney County, KS, was avaluble from the field measurcments library at Purdue/LARS More than one thousand spectra were avalable from each location and collecion date The response functions were sampled in wavelength using narrow windows of $002 \mu \mathrm{m}$ over the range $04 \leqslant$ $\lambda \leqslant 24 \mu \mathrm{m}$

The optimal set of basis functions is found numerically by estimatung the covariance matrix from the sample response funcuion Maximum likelihood estumates of the mean and covariance matrices are given by

$$
\bar{X}=F\{X\} \approx \hat{\bar{X}}=\frac{1}{N_{s}} \sum_{i=1}^{N_{r}} X_{l}
$$

and

$$
K=\frac{1}{N_{s}} \sum_{i=1}^{N_{s}}\left(X_{i}-\hat{\bar{X}}\right)\left(X_{1}-\hat{\bar{X}}\right)^{T}
$$

where $N_{s}$ is the number of sample functions dvalabie and $X_{1}$ is the ith sample vector The covarance is the kernel in the lines integral equition whose solutions are the optimal basis functions or eigenvectors A remarkably stuble and accurate methed for numenially computing the cigenvalues and eigenlectors was publushed by Grad and Brebner $|6|$

The eigenveciors are used to perform the hnedr transformation

$$
y_{1}=I^{T}(X-\stackrel{\grave{X}}{)})
$$

on the data set The class conditional statistics are computed using the transformed data

In order to compare the performances of two systems an algonthm which estumates the probabulity of correct classificauon for an $M$ class problem, given the class conditional multtvariate Gaussian statistics, was used $[16]$ This algorithm, which is based on the stratified posterior esumdtor $[15]$, was found to be accurate withm one-half of 1 percent

The expermental system also included an ability to simulate (suboptimal) practical sensors Although nearly any sensor
TABLE I

Spectral Bain locations for Tho Practical Sensor Disigas"

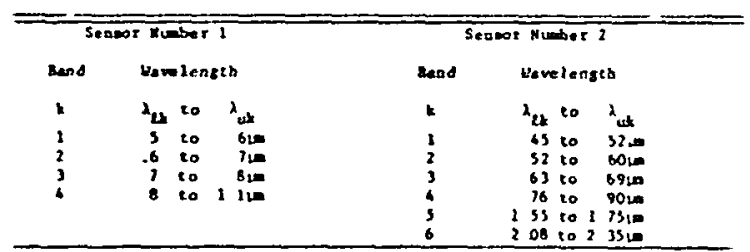

"The band edges of these sensors were selected to coincide with the nominal bandwidths of the MSS of Landsats 1.2. and 3, and those of the TM of Landsat D

characteristic could be simulated, most of the sensors which we.e simulated consisted of a small set of rectangular basis functions, $1 \mathrm{e}$,

$$
\psi_{+}(\lambda)= \begin{cases}10, & \lambda_{1 k} \leqslant \lambda \leqslant \lambda_{u k} \\ 00, & \text { otherwse }\end{cases}
$$

where the $\lambda_{l k}$ and $\lambda_{u k}$ are the lower and ipper limts of the spectral bands The spectral bands of two suboptimal sensors which were implemented are listed in Table I

\section{RrSULTS}

It became necessary during this research to create a means for incorporatung certain iypes of anculary informition into the optimization process The reason tor this can best be lllustrated with an example We first determine the uptumll fedtures, $\left\{\phi_{k}(\lambda)\right\}$, for a data set using the unform weight function of Fig 9 Plots of the first four eigenvectors for this case are shown in Fig 10 Now the shape of an eigenfunction is instructive in the application because whenever an ergenfunctuon is large (enther positive or negatuve) at a gven $\lambda$, it implies that that wavelerigh is important in representmy the given ensemble and, the refore, perhaps also in classifying it

It was obseived in this example that the eigervectors dre dommated at least in the case of $k=1$ and 4 by components in the bands near 14 and $19 \mu \mathrm{n}$ These bands are domindted by water absorption in the atmosphere, and it is hnown a pnon that very little solar flux reaches the earth's surface in them Thus these regions near 14 and $19 \mu \mathrm{m}$ represent noise rather than signal, dnc under test, the eigenvectors which were sens1tive to these bands contributed very little to the classification performance Using a second weight function which assigns a very small weight in the water abserption bands (Fig 11) the inlluence of the spectrum in the water absorption bands is significantly reduced, and a marked improvement in classifica. Iton performance $(\mathrm{e} g$, a classification eryor rate reduction from 19 ó percent to 118 percent for a six-feature classificaucn) is observed

It is a characieristic of the Karhunen-Loeve representation that speciral utervals with the grcatest ensemble varation dre guen greatest emphasis Some of this ensemble vanation may be expected is be information-beanng (signal) and some not (noise). As can be seen by this cxample, the woighting function provides a convenient means to incorporate into the feature design pror knowledge about whether ensemble vand. tons in a given range are signal or nosse In the remaunder of 


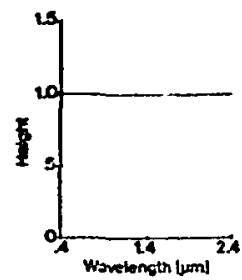

Fig. 9 Weight function number 1
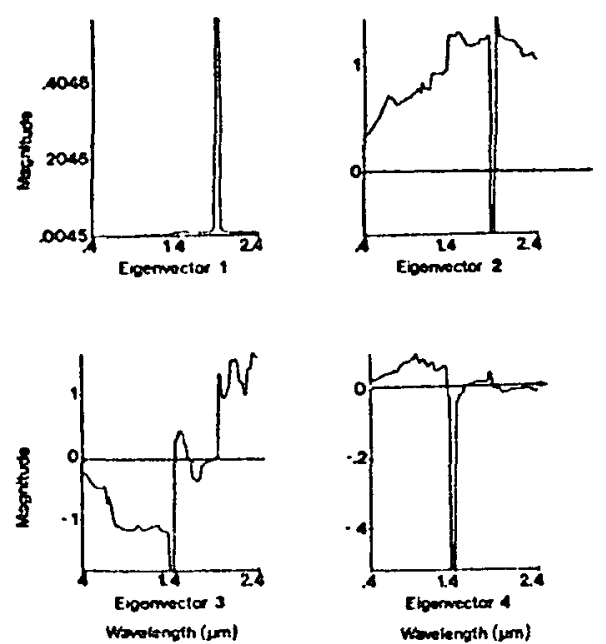

Iig 10 rirst four optimum basis functions using weight function nuniber 1 over Willams County, May 8, 1977, data

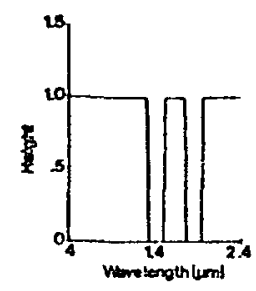

Tig 11 Weight function number 2

the results presented, the weighting funcuion of Fig 11 was used Two other weighting functions have been tested [16]. tie choice of which is the best weighting function is thought to depend on a number of factors not all of which are well understood

Results for the design of the optumal sensor for one of the six sets o? data are presented in Figs 12-14. ${ }^{1}$ The data from the stratum was collected over Willams County, ND, on May 8, 1977 The three classes represented in this data set were spring wheat, summer fallow, and pasture Since the data were taken relatively eariy in the growing season, the wheat canopy was still quite sparse which leads one to expret the wheat class to resemble spectrally bare sul or fallow In Fig 12 the expected mean square error is plotted as : function of the aum-

\footnotetext{
'The results for the other five data seis, which were from different times of the year at the North Dakota site and a Kansas site, are coniared in $(16)$
}

ber of terms in the expansion Rapid convergence in the first few terms is demonstrated in thus graph

The first eight weighted eigenvectors are plotted in Fig 13 Note that the riagnitude of the first eigenvector has the general shape of a typical spectral response of soil, since the predominant response in two of the three classes is soll, this first eigenfunction may be thought of as the average response over the ensemble The second eigenvector tends to divide up the spectrum into three to four relatively broad regions As the number of terms in the expansion is increased, the terms that are added require higher spectral resolution to reduce meansquare error, l.adicating that spectral fine structure may be in. creazingly important. We will comment further on thus later.

In Fig 14 the estumated probability of correct classification is graphed as a function of the expected mean-square error It is scen that at least the first eight basis functions contribute significantly to the classification accuracy The numbers in parentheses on $F_{1 g} 13$ indicate the order in which the features were chosen by a feature selection processor ${ }^{2}$ The relatively broad bands of $\phi_{2}(\lambda)$ are indicated as of greatest importance to class discrimination but anparently rather quickly thereafter the finer spectral structure represented by $\phi_{6}(\lambda)$ becomes important

To complete the design illustration, the procedure was used to determine a set of physically realizable rectangular spectral bands $S i x$ to ten bands were required based on a study of the dimensionality An intral sel of band edges was chosen based on an examination of the eigenvectors of the May 8 data set From (1a) it is observed that reguons of the spectrum that are significantly different from zero for a particular eigenvector may contan important information This. together with the feature ordenng determined by a standard feature selection atgonthm, indicates spectral inteivals unportant for uscrimination Zero crossings of the eigenvectors may be possible indicat.uns of band edges

Based upon such a study of the optima! unctions a set of rectangular spertral bands was chosen. The final set of band edges for the example design is presented in Table II In Fig :5, companson of the two simulated sensors of Table 1 and the optumum set is made on the basis of classification per. formarice for the May 8 data The first ten optimal basis func. tions were used from the optimal design, where 10 features provide a small mean-square crror yet keep the computational difficulties involved with high dimensiona! systems to a reasonable level As shown in Fig 15, the inur-band sensor 1 compares rather poorly with the best four ${ }^{3}$ optimal basis functrons, showing sensur 1 to be far from optumal for this set of classes Sensor 2 is an improvement over sensor 1, but stul somewhat lower in performance than desirable The eight. band example design, however, demonstrates very good performance relative to the performance of the ten feature opirmal se:. Also, the expected mean-square error is significantly reduced over that of sensors 1 and 2 It should be

\footnotetext{
${ }^{2}$ The feature selccion scheme is based upon maximizing the arerage interclass-pair divergence The detavis are in $[16\}$

"The term "best" refers here to those chosen by a feature selection algonthrn 8 best fot discriminaling betteen the design set classes
} 


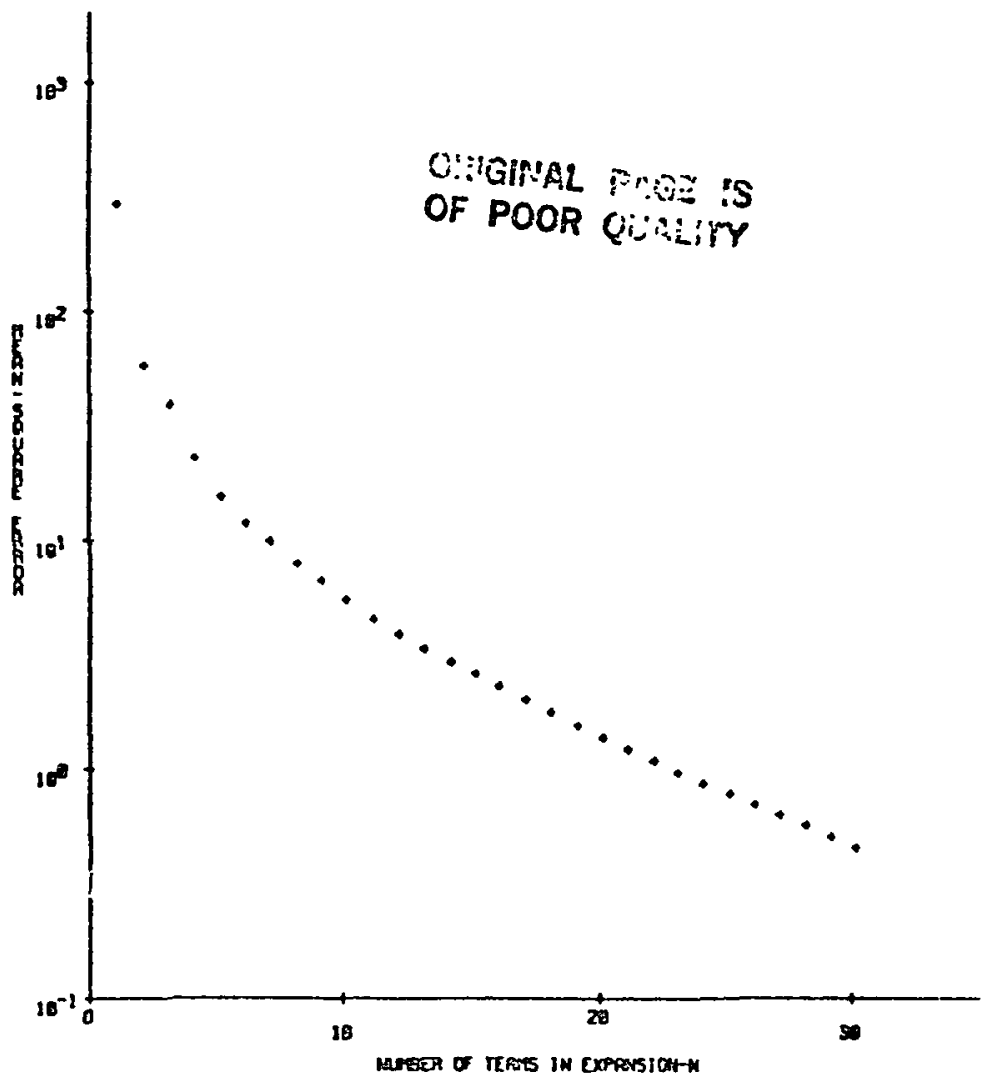

Fig 12 Expected mean-square error as a functuon of the number of terms in the Karhunen-Loeve expansion for Whliams County, May 8 , 1977, using weight function number 2
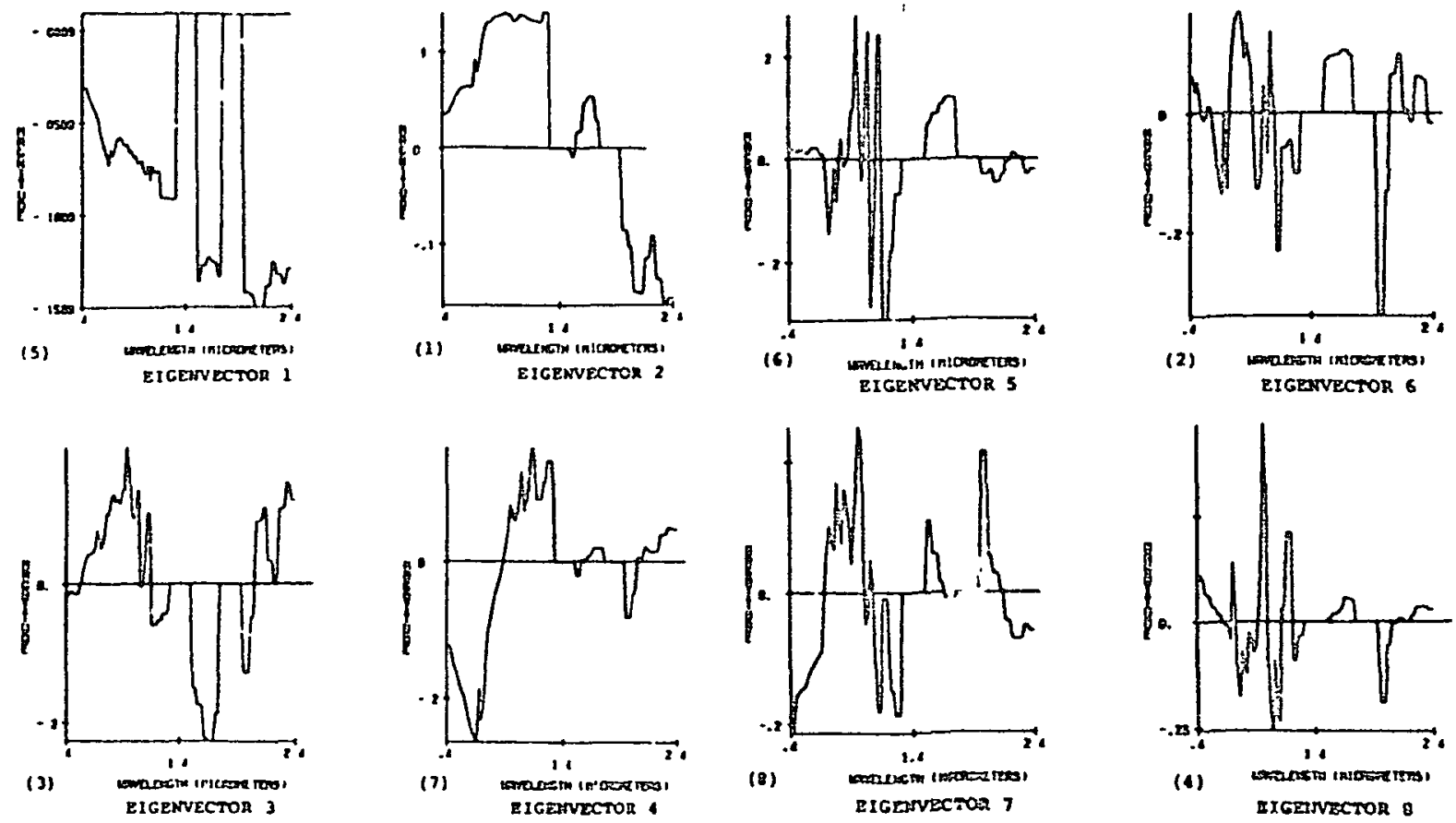

F18 13. First eight eßzenvectors for Whimms County, May 8, 1977, uons yeght furction auribor 2. 


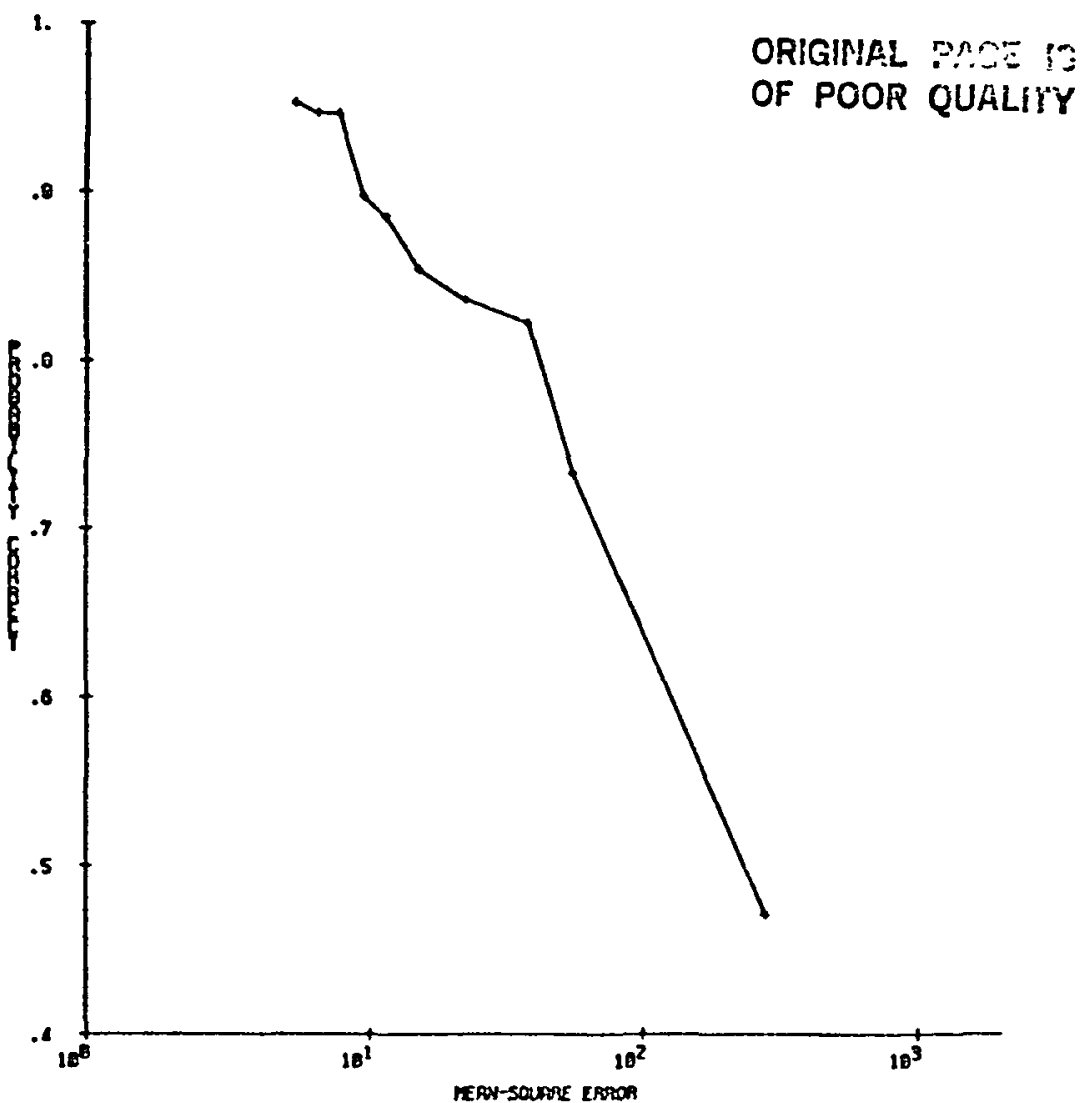

Fig 14 Estimate of probability of correct classification versus expected mean-square error Willams County, May 8, 1977, using weight function number 2

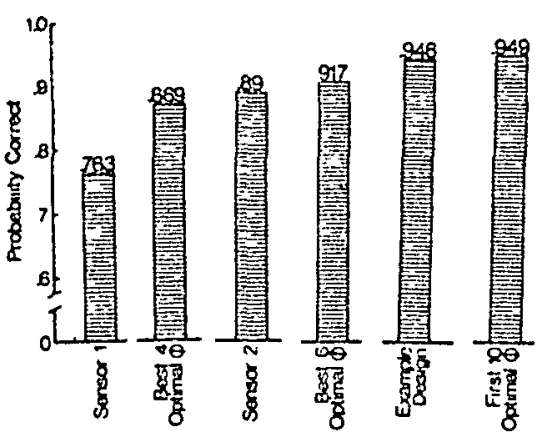

Fig 15 Companson of sensor performance Willams County, May 8 , 1977

TABLE II Spectral band Locations for the Example Design

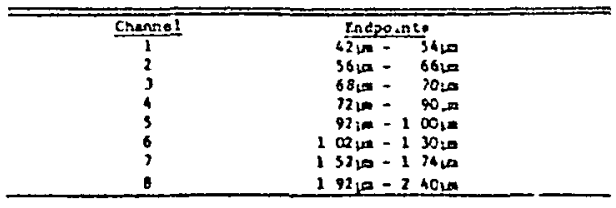

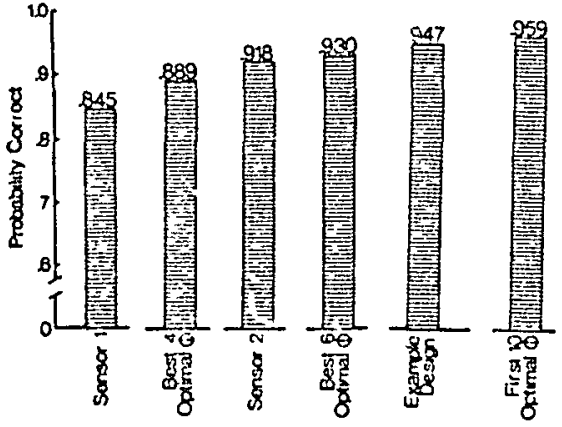

Fig 16 Companson of sensor performance Average of six cases

pointed out that these compansons of classification performance are based on a particular set of information classes and the results may be different if different classes were chosen The reduced representation error may imply increased robustness in performance for differing information classes

The performance was evaluated for the six data sets and the average performance for each of the sensors is shown in Fig 16 Again the experimental sensor is quite close in performance to the optimal, a difference of about one percent. 
IEEE TRANSACTIONS ON GEOSCIENCE AND REMOIE SENSING, VOL. GE-18, NO. 2. APRIL 1980

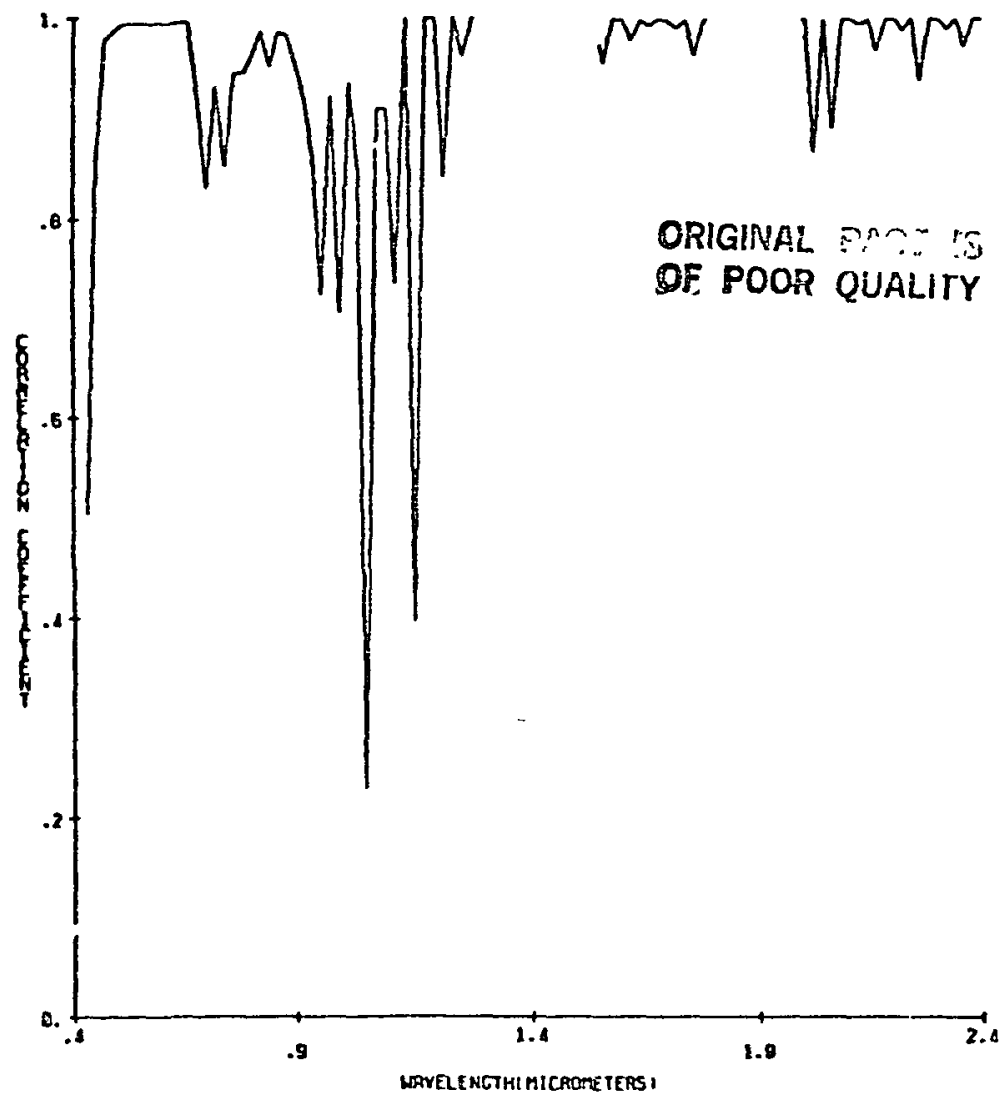

Tig 17 Correlation cocficients versu= wavelength for Willams County, May 8,1977

Although the primary purpose of this work was to develop a design procedure for sensurs, important contributions to the understanding of the scene can be ganed Properties such as signal dimensionality for a given stratum, maximum possible claes separability, the spectral resolution required, and the accuracy of spectral representation required to obtain a given level of performance can be studied

The dimensionality of the ensemble can be defined as the number of terms in the expansion necessary to represent the ongnal waveform to the desired accuracy For the information classes used on the six data sets the dimensionality was between six and eight Some of the strata required fewer terms in the expansion to obtain a good representation and good performance while others required more terms

A review of the cigenvectors of Fig 13 shows an unexpected amount fine structure, particularly in the region from 066 to $126 \mu \mathrm{m}$ as previously noted Up to this time it had often been observed that spectral bands very near to one another tend to be highly correlated and thus redundant To investigate this structure a bit further the correlation coefficient between each band of width $002 \mu \mathrm{m}$ and its nearest neighbor was calculated The results are shown in Fig 17 Based upon previously hnown results one might expect the graph of the figure to deviate little from unity The fact that it does de. viate significantly from unty changing significantly in very narrow bands may be further evidence that there is useful information in the spectral fine structure

\section{Conclusion}

The design of the spectral bands for multispectral instruments has been an important matter for a number of years In the past such design lias of necessity been carried out as a spectral band selection problem using in a subject" 'e manner the direct application of expenence and judgment Nonover. lapping bands were selected one-by-one based upon the current understanding of reflectance phenomena Each band was generally selected on its own indwidual meters because evalu. ating sets of bands is difficult to do without computational ands A typical cxample of this process was the design of the Thematic Mapper bands i 7$\}$ Although this procedure has served adequately to thr tume, as the level of sophistication of applications and, therefort of data needs continues to grow, it seerns clear that more quantitative and objective design tools are needed It was this need to which the work reported herein was directed

$A$ s has been seen the design technıque which resulted utilizes an empirical stochastic scene model as the best currently feasible means for definng quantutatively the scene and its information and nosse content Since not all sensor system limitations can be analytically specified, the technique utilizes an optimal disign calculation but it still requires engineering judgnent as the best means for resolung the tradeoff of more tangible factors with those which are less tangable it is by 110 means intended as an "dutomatic" design riocedure 
The optumal design calculation was established utuluzing an overall performance measure, probability of correct classifica. tion, and an intermediate one, spectral representation error averaged over the ensemble. One can argue that it is overall system performance which is, after all, the most important. However, a specific performance measure calculation can only be carried out with regard to a specific set of classes Different applications frequently require the same data set to be classified into different class sets; thus ore desires robustness with regard to various class sets as well in a feature set. The hy. pothesis used here is that a $u$ icern for representation accuracy will tend to insure this :obustness, thus the bilateral approach to performarce index

The demonstration presented here of the design technique appea.s to warrant the conclusion that the calculation procedure provides a substantial ald to the overall design process With relatively limited effort a feature set with good overall performance was obtained On the other hand, the band set given in Table II should by no means be regarded as worthy of consideration for implementation as is The ensemble definstion and sampling were not an important point in this work and would require much more detaled and careful considerdion than they received here The same is true of the band set and its comparison to alternative chosces

And finally, we agan draw attention to the use of the tools of this design procedure for carry!ng out more basic research into understanding the scene itself and its spectral cnaracteristucs By being able to determine and qudntitatively assess the information-beanng attributes of scene spectral characteristics, the ability to study potentially important characteristics of the scene is greatly faclitated

\section{REFERENCES}

(1) R B Ash, B, irmation 7hcory New York Wiley, 1967

(2) W B Davenport and W I Root, An Introxluction to the Theory of Random Sigrals and Nolse New York MoGraw-Hill, 1958

(3) R B Crane, W A Malula, and W Ruchardson, "Sutabulty of the normal density assumption for processing muluspectrai scanner data," IEEE Trans Ceosa Electron, vol GE-10, pp 15\%-165, 1972

[4] R O Duda and P E Hart, Patlern Classification and Scene Analysis New York Wuley, 1973

[5] $k$ Fukunaga, Introduction to Statistical Pattem Recognttion New York Academuc, 1972

[6] J Grad and M A Brebner, "Eigenvalues and eigenvectors of a real general matrix, Algonthm 343," 'ssoctation for Computing Machinery, Corrm, vol 11, no 12, pp 820-826, 1968

[7] J I Harnage ar.! D A Landg ube, "Landsat-D Thematuc Mapper Technical Working Group- Final Report," NASA/Johnson Space Centec report no JSC-90797. Housion, Texas, 1975

(8) R A Holmes and R B MacDonald, "The physical basis of system design for remote sensing in agriculture," Proc IEEt, vol 57. pp 629-639, 1969

[9] R M Hoffer, "Biological and physical considerations in applying computer-aided andysis techniques to remote sensor data." in Remote Sensing The Quantilative Approach. P H Swain and $S M$ Davis, eds New York McGraw-Hil, 1978

$[10]^{G} F$ Hughes, "On the mean accuracy of statistucal patten recog. nizers," IEEE Trans Inform. Theory, vol IT-14, pp 55-63, 1968

[11] D A Landgrebe, "Useful inforn ation from multispectral image data another look," in Remore Sensing The Quantitolive Approoch, P H Swaln and S M Davis, eds New York McGrawHill, 1978

[12] B G Mobassers, C D McGulem, and P E. Anuta, "A parametnc multiclass Bases error estumator for the multuspectral scanner spatial model performance evaluation," ph D disscrtation, LARS Techncal Rep 061578, Lab for Applications of Rerrote Sensing, Purdue Univ, West Lafayette, IN, 1978

[13] A Papoulus, Probability. Random Vanables and Srockastic Processes New York McGraw-Hill, 1965

[14] P J Ready, P A Wintz, S: Whitut, and D A. Landyrebe, "Effects of compression and random noise on multuspectral data," in Proc of the 7th Int Symp or: Remote Sensing of the Environmemt, Ann Arbor, MI, 197]

[15] S J Whutsitt and D A Landgrebe, "Frror estimation and scpa. rabiluty measures in feature selection for multuclass pattern recognition," Ph D dissertation, LARS inform Note 082377, LARS, Puidue, West Lafayette, IN, 1977

[16] D J Wiersma and D A Landyrebe, "The analytical design of spectral measurements for multuspectral remote sensor systems," Ph D dissertation, LARS Tech. Rey \#122678, Purdue Uniiersity, West Lafayette, IN, 1979

[17] H L VanTrees, Detection. Estumation, and Mocituation TheoryPart I New Yosk Wley, 1968

\section{CRIDINAI PFCE IS \\ OF POOR QUALITY}




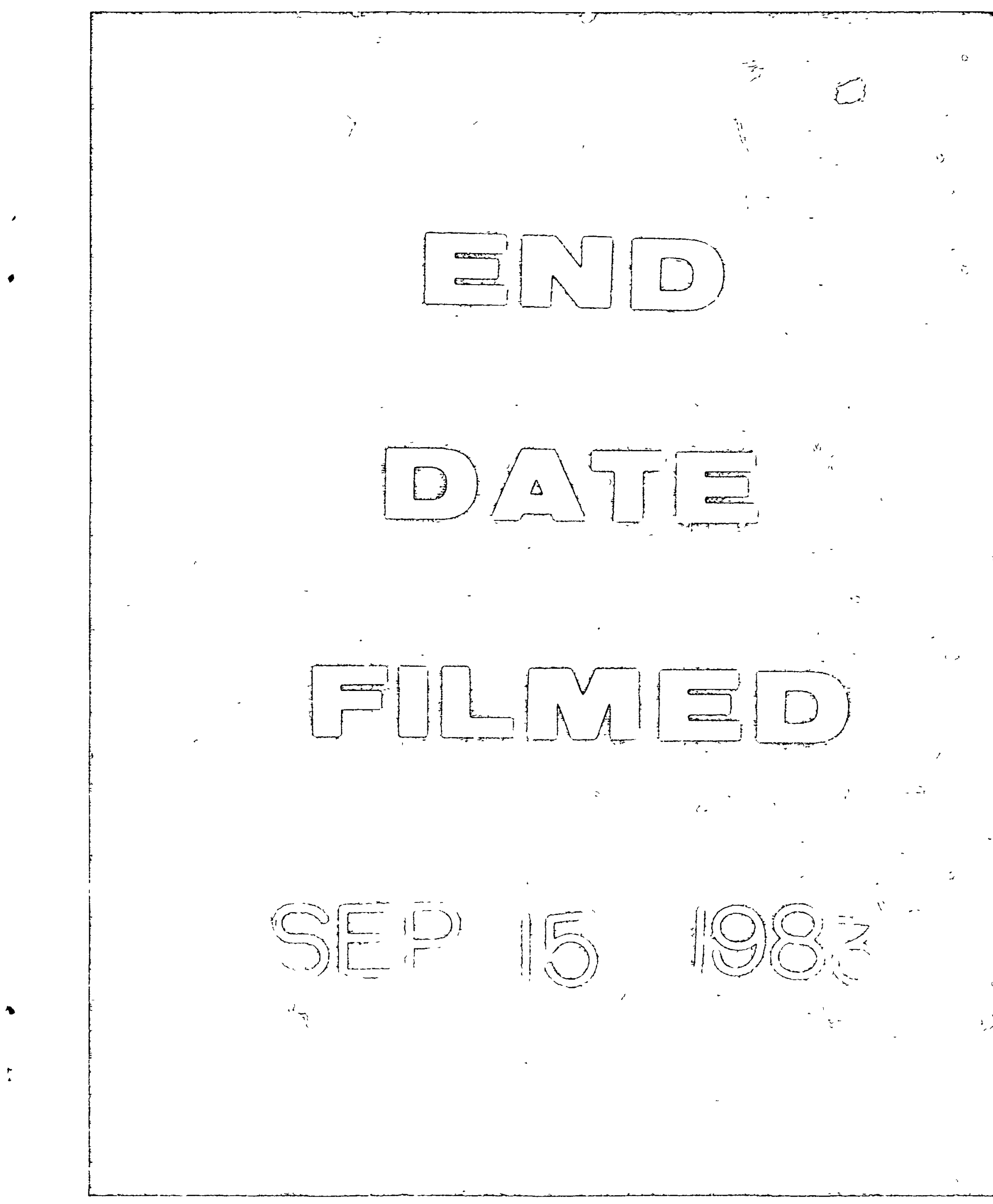

